\title{
Evaluation Indexes Design for Sustainability of the Intelligent Systems Based on the Differential Equation
}

\author{
ChaoXi Zhang \\ School of North China Electric Power University, Baoding 071003, China; \\ 1361495300@qq.com
}

Keywords: AHP, difference equation model, sustainability development evaluation

\begin{abstract}
Our paper provide select human health, food security, equitable sustainable development, local environmental quality, and energy access, livelihoods, community vulnerability, and access to clean water as indexes to evaluate whether a country is sustainable. With the research of the Intelligent Systems Analytic, we can clearly define when and how a county is sustainable or unsustainable and obtain countries that need the most support and intervention. by collecting typical research review report, according to the national population census data, the difference equation model is established to predicting the aging of the population dividend and results. Then, according to the sex ratio at birth and fertility, we forecast the population development tendency, looking forward to the necessity of "two child policy", which it is concluded that separate two child policy has great impact on the future development of our country and the necessity of implementation. Finally we obtain the solution of AHP.
\end{abstract}

\section{Introduction}

Sustainable development is defined by the 1987 Brundtland Report as "development that meets the needs of the present without compromising the ability of future generations to meet their own needs."

The United Nations (UN) predicts the world's population will level at 9 billion people by 2050 . This, coupled with increased consumption, places a significant strain on the earth's finite resources. International aid agencies, planners, governments, and non-profit organizations are committed to construct an evaluation system for sustainable development. Therefore, striving towards a sustainable future has never been more imperative.

\section{The definition and model of Evaluation Indexes}

According to the definition of sustainable development and the principle of evaluation indexes, we finally select eight indexes to develop an evaluation system, which are contains health human, food security, access to clean water, local environmental quality, energy access, livelihoods, community vulnerability, and equitable sustainable development.

\section{Human Health}

The damaging effects of human impacts on natural environment have had a serious health threat on human beings themselves, and become an important factor in economic and social sustainable development [1]. So we select health expenditure per capita, improved sanitation facilities (\% of population with access)and life expectancy at birth, total (years) by Principal Component Analysis method, which cumulative contribution rate more than $80 \%$. Let hh denote the index of human health:

$$
h h=h e+s f+l e
$$

Where he denotes the index of health expenditure per capita for i year, sf denotes the index of improved sanitation facilities (\% of population with access) for i year and le denotes the index of Alternative and life expectancy at birth, total (years)for i year. 


\section{Food Security}

Food is an essential subsistence substance for human survival and development, which is closely related to the life and health of the people. If food security cannot be guaranteed, it will threaten human survival and development and affect the sustainable development of human society and economic. According to the data from the World Bank Group, we use Global food safety index to measure food security of a country.

$$
f s=g f
$$

Where fs denotes food security of a country for i year, and gf denote Global food safety index for i year.

\section{Access to Clean Water}

As the rapid increase in global population and per capita income levels, global clean water scarcity is emerging. The condition access to water is an important part that reflects the sustainability degree of a country. Therefore, we apply Principal Component Analysis method and collect data that contains improved water source, rural (\% of urban population with access) and improved water source, urban (\% of urban population with access) from World Bank Group. Let w denote the index of accessing to clean water:

$$
w=r+u
$$

Where $\mathrm{r}$ denotes improved water source in rural areas for i year, and u denotes improved water source in urban areas for i year.

\section{difference equation model}

The age group the number of people $i$ th remember time formula $x_{i}(k), k=0,1,2 \ldots, i=1,2, \ldots n$ fertility rate of the $\mathrm{i}$ is $b_{i}$, The $\mathrm{i}$ th age group of the population coefficient rate for children and adolescents is $d_{i}$, Survival rates is $s_{i}, s_{i}=1-d_{i}$, we assumpt that $b_{i}$ and $d_{i}$ do not change with the change of $\mathrm{k}$, this assumption is reasonable in a stable environment.

$$
x_{i}(k+1)=\sum_{i=1}^{n} b_{i} x_{i}(k)
$$

Time period $\mathrm{k}+1$, the $\mathrm{i}+1$ th Age group population factor in young adultsis the period $\mathrm{k} i$ th The number of age groups to survive, that is:

$$
x_{i+1}(k+1)=s_{i} x_{i}(k), i=1,2, \ldots, n-1
$$

Tiem period K The distribution of the variables for population according to age groups:

$$
x(k)=\left[x_{1}(k), x_{2}(k), x_{3}(k), x_{4}(k)\right]^{T}
$$

Matrix fertility composed of rate and survival rate: $b_{i} \boldsymbol{s}_{\boldsymbol{i}}$

$$
L=\left(\begin{array}{cccc}
b_{1} & b_{2} & b_{3} & b_{4} \\
s_{1} & 0 & 0 & 0 \\
\cdots & s_{2} & 0 & \cdots \\
0 & \cdots & s_{3} & 0
\end{array}\right)
$$

then (1) 、 (2) suggest:

$$
x(k+1)=L x(k), k=0,1,2, \cdots
$$


When the matrix $L$ and vector $x(0)$ according to the age group of the initial distribution is known, According to the distribution of age groups the predictable time k crowd:

$$
x(k)=L^{k} x(0), k=1,2, \cdots
$$

We make the age divided into four groups, the country's population being divided into 0 to 14,15 to 49,50 to $59,60-90$ four ages. At this time there exsit:

$$
L=\left(\begin{array}{cccc}
b_{1} & b_{2} & b_{3} & b_{4} \\
s_{1} & 0 & 0 & 0 \\
0 & s_{2} & 0 & 0 \\
0 & \cdots & s_{3} & 0
\end{array}\right)
$$

According to the China statistical yearbook we can check data from 2000-2008 migrants move rate and population coefficient rate in children and adolescents $S_{i}$.

\section{Conclusion}

The final destination of our model, is to lay the good foundation to find the Most suitable pattern for the sustainable development of a country. With the research of the Intelligent Systems Analytic, we can clearly define when and how a county is sustainable or unsustainable and obtain countries that need the most support and intervention. Finally we obtain the solution of AHP. We can clearly define when and how a county is sustainable or unsustainable. We can also obtain countries that need the most support and intervention.

\section{Reference}

[1] Yang Zhousheng. Environment and Human health [M].Anhui Normal University Press, 2011.

[2] Deng Xue, Li Jiaming, Zeng Haojian. Research on Calculation Methods of AHP Weight Vector and Its Application [J]. Mathematics in practice and theory, 2012, 07:93-100.

[1]J. van der Geer, J.A.J. Hanraads, R.A. Lupton, The art of writing a scientific article, J. Sci. Commun. 163 (2000) 51-59. Reference to a book:

[2]W. Strunk Jr., E.B. White, The Elements of Style, third ed., Macmillan, New York, 1979. Reference to a chapter in an edited book:

[3]G.R. Mettam, L.B. Adams, How to prepare an electronic version of your article, in: B.S. Jones, R.Z. Smith (Eds.), Introduction to the Electronic Age, E-Publishing Inc., New York, 1999, pp. 281-304.

[4]R.J. Ong, J.T. Dawley and P.G. Clem: submitted to Journal of Materials Research (2003)

[5]P.G. Clem, M. Rodriguez, J.A. Voigt and C.S. Ashley, U.S. Patent 6,231,666. (2001)

[6]G.R. Mettam, L.B. Adams, How to prepare an electronic version of your article, in: B.S. Jones, R.Z. Smith (Eds.), Introduction to the Electronic Age, E-Publishing Inc., New York, 1999, pp. 281-304.

[7]R.J. Ong, J.T. Dawley and P.G. Clem: submitted to Journal of Materials Research (2003)

[8] Information on http://www.weld.labs.gov.cn 